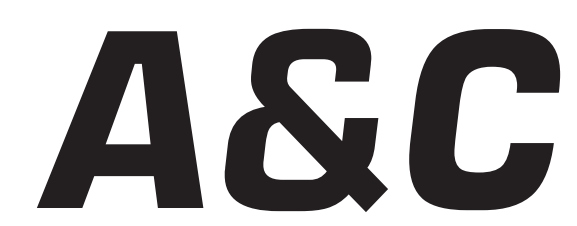

Revista de Direito Administrativo \& Constitucional

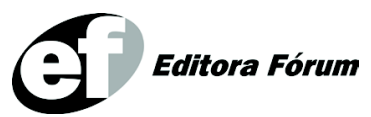

ISSN 1516-3210 


\section{A\&C REVISTA DE DIREITO ADMINISTRATIVO E CONSTITUCIONAL}

IPDA

Instituto Paranaense

de Direito Administrativo

Direção Geral

Romeu Felipe Bacellar Filho

Direção Editorial

Paulo Roberto Ferreira Motta

Direção Executiva

Emerson Gabardo

Conselho de Redação

Edgar Chiuratto Guimarães

Adriana da Costa Ricardo Schier

Célio Heitor Guimarães

\section{Conselho Editorial}

Adilson Abreu Dallari

Alice Gonzáles Borges

Carlos Ari Sundfeld

Carlos Ayres Britto

Carlos Delpiazzo

Cármen Lúcia Antunes Rocha

Celso Antônio Bandeira de Mello

Clèmerson Merlin Clève

Clóvis Beznos

Enrique Silva Cimma

Eros Roberto Grau

Fabrício Motta

Guilhermo Andrés Muñoz (in memoriam)

Jaime Rodríguez-Arana Muñoz

Jorge Luís Salomoni

José Carlos Abraão
José Eduardo Martins Cardoso
José Luís Said
José Mario Serrate Paz
Juan Pablo Cajarville Peruffo
Juarez Freitas
Julio Rodolfo Comadira
Luís Enrique Chase Plate
Lúcia Valle Figueiredo
Manoel de Oliveira Franco Sobrinho
(in memoriam)
Marçal Justen Filho
Marcelo Figueiredo
Márcio Cammarosano
Maria Cristina Cesar de Oliveira

Nelson Figueiredo

Odilon Borges Junior

Pascual Caiella

Paulo Eduardo Garrido Modesto

Paulo Henrique Blasi

Paulo Neves de Carvalho (in memoriam)

Paulo Ricardo Schier

Pedro Paulo de Almeida Dutra

Regina Maria Macedo Nery Ferrari

Rogério Gesta Leal

Rolando Pantoja Bauzá

Sérgio Ferraz

Valmir Pontes Filho

Yara Stropa

Weida Zancaner

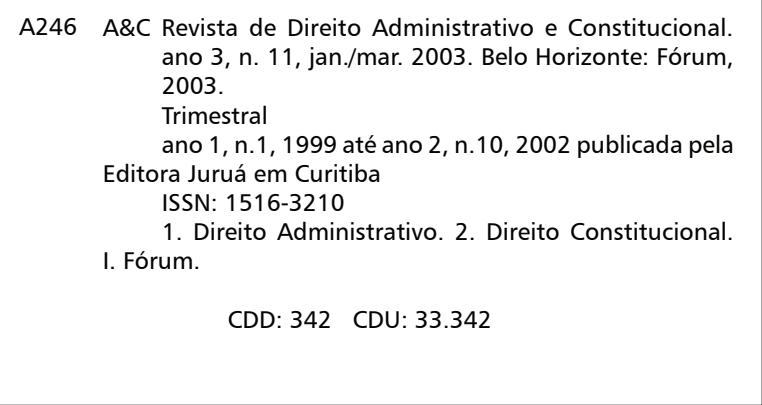

(C) Editora Fórum Ltda. 2007

Todos os direitos reservados. É proibida a reprodução total ou parcial, de qualquer forma ou por qualquer meio eletrônico ou mecânico, inclusive através de processos xerográficos, de fotocópias ou de gravação, sem permissão por escrito do possuidor dos direitos de cópias (Lei nº 9.610, de 19.02.1998).

Editora Fórum Ltda

Av. Afonso Pena, $2770-15 \% 16^{\circ}$ andar - Funcionários

CEP 30130-007 - Belo Horizonte/MG - Brasil

Tel.: 08007043737

Internet: www.editoraforum.com.br

e-mail: editoraforum@editoraforum.com.br
Editor responsável: Luís Cláudio Rodrigues Ferreira Projeto gráfico e diagramação: Luis Alberto Pimenta Revisora: Olga M. A. Sousa

Pesquisa jurídica: Fátima Ribeiro - OAB/MG 74868

Bibliotecária: Leila Aparecida Anastácio

CRB 2809/MG 6ª região

Os conceitos e opiniões expressas nos trabalhos assinados são de responsabilidade exclusiva de seus autores.

Impressa no Brasil / Printed in Brazil

Distribuída em todo Território Nacional 


\title{
Participação popular no processo legislativo
}

\author{
Adriano Sant'Ana Pedra \\ Doutorando em Direito Constitucional (PUC/SP). Mestre em Direitos e Garantias Constitucionais \\ Fundamentais (FDV). Coordenador e Professor do Curso de Pós-Graduação em Direito Público \\ da Faculdade de Direito de Vitória (FDV). Professor da Escola da Magistratura do Espírito Santo \\ (EMES). Procurador Federal.
}

Palavras-chave: Participação popular. Democracia participativa. Plebiscito. Referendo. Iniciativa popular.

Sumário: 1 Introdução - 2 Plebiscito - 3 Referendo - 4 Iniciativa popular 5 Veto popular - 6 Considerações finais - Referências

\section{Introdução}

A democracia repousa sobre dois princípios fundamentais, que lhe dão a essência conceitual. O primeiro é o princípio da soberania popular, segundo o qual o povo é a única fonte do poder, que se exprime pela regra de que "todo o poder emana do povo" (parágrafo único do artigo $1^{\circ}$ da CF). O outro é a participação, direta ou indireta, do povo no poder, para que este seja efetiva expressão da vontade popular.

A participação popular constitui-se em um comportamento político no qual o cidadão toma parte das decisões do Estado. Assim, embora possamos dizer que não é somente nas democracias que se pode verificar a participação política, esta é imprescindível para aquelas.

A Constituição brasileira prevê mecanismos de participação ativa não apenas através do voto. O cidadão não pode reduzir-se ao eleitor, mas deve ser também um indivíduo participante e controlador da atividade estatal. A democracia participativa implica o exercício direto e pessoal da cidadania nos atos de governo. Tais mecanismos da democracia direta devem conviver harmonicamente com os institutos da democracia representativa. Afinal, a defesa de uma democracia participativa não implica em advogar que todas as formas de representação devam ser necessariamente abolidas.

Neste contexto, busca-se aqui analisar os instrumentos através dos quais o cidadão pode participar diretamente da formação da vontade estatal, participando do processo legislativo. Serão considerados os principais mecanismos e os aspectos que os envolvem. Tais instrumentos 
de participação direta do povo serão regulados pela Constituição, porque estes mecanismos surgem concomitantemente com a organização do Estado. Um procedimento democrático é imprescindível para alcançar a legitimidade constitucional. Qualquer que seja o modo utilizado para corporificar a vontade constituinte do povo, é necessário observar o procedimento adotado ao longo deste processo.

\section{Plebiscito}

O plebiscito ${ }^{1}$ é uma consulta prévia $^{2}$ formulada ao povo, onde o cidadão é chamado a manifestar-se sobre um fato político ou institucional, de acentuada relevância, de natureza constitucional, legislativa ou administrativa, para aprovar ou denegar o que lhe for submetido. A decisão soberana do plebiscito vincula as autoridades públicas atingidas, que não poderão adotar caminhos diversos daqueles definidos pelo povo. Dependendo do resultado do plebiscito, ${ }^{3}$ a providência será ou não adotada, certo que a decisão do povo não pode ser modificada pelo poder constituído, o que significa dizer que a decisão plebiscitária é sempre vinculante. Afinal, não se constitui o plebiscito em mera pesquisa de opinião, mas sim na expressão da vontade popular.

O plebiscito pode submeter ao povo uma proposta normativa, que pode ser constitucional, legal ou até mesmo infralegal, ou pode referir-se a uma consulta sobre um determinado tema. Merece frisado que o plebiscito deve ser utilizado em consultas de acentuada relevância, isto é, ele não deve ser utilizado para a tomada de decisões ordinárias, para as quais existem os meios próprios e representantes escolhidos para estes fins.

O plebiscito, assim como o referendo, não tem restrição material, isto é, podem tratar de qualquer tema, embora existam situações que exijam a manifestação direta da população, como os $\S 3^{\circ}$ e $4^{\circ}$ do artigo 18

\footnotetext{
O vocábulo plebiscitum é formado por dois elementos: plebis (plebe) e scitum (decreto). O termo tem origem nos decretos emanados das Assembléias da plebe romana. O plebiscito deliberava acerca do interesses da plebe.

2 O artigo $2^{\circ}, \S 1^{\circ}$, da Lei $n^{\circ} 9.709 / 98$, dispõe que "o plebiscito é convocado com anterioridade a ato legislativo ou administrativo, cabendo ao povo, pelo voto, aprovar ou denegar o que lhe tenha sido submetido".

3 Se a consulta é prévia, prefere-se utilizar a terminologia "plebiscito" do que "referendo consultivo", de que se valem alguns autores. Cf. DALLARI. Elementos de teoria geral do estado, p. 154: "Alguns preferem considerar apenas um referendum consultivo". Cf. FERREIRA. Curso de direito constitucional, p. 168: "Referendum consultivo, quando o povo é previamente solicitado para exprimir a sua opinião sobre a lei, e a sua antítese, ou referendum pós-legislativo, que é a manifestação popular sobre a lei já votada pelo Parlamento".
}

A \& C R. de Dir. Administrativo e Constitucional, Belo Horizonte, ano 7, n. 27, p. 109-120, jan./mar. 2007 
da CF e o artigo $2^{\circ}$ do ADCT. A técnica plebiscitária encontra-se presente no texto constitucional brasileiro em três artigos. $\mathrm{O}$ artigo 14 aponta o plebiscito, ao lado da iniciativa popular e do referendo, como um dos meios do exercício da soberania popular, sendo um instrumento da democracia participativa. O artigo $18, \S 3^{\circ}$, da CF, cuida do plebiscito para incorporação, subdivisão ou desmembramento de Estados, bem como formação de novos Estados ou Territórios Federais, enquanto que o $\S 4^{\circ}$ deste mesmo artigo trata do plebiscito para criação, incorporação, fusão e desmembramento de Municípios. A Constituição ainda estabelece, em seu artigo 49, XV, que é da competência exclusiva do Congresso Nacional convocar o plebiscito e autorizar referendo.

Além dessas três hipóteses previstas no corpo normativo da Constituição propriamente dita, o artigo $2^{\circ}$ do ADCT tratou do plebiscito extraordinário e específico, para escolher entre a forma republicana ou monárquica de governo, e ainda entre o sistema parlamentar ou presidencialista, marcado inicialmente para o dia 7 de setembro de 1993 e antecipado para 21 de abril do mesmo ano.

\section{Referendo}

O referendo ${ }^{4}$ consiste em consulta posterior ${ }^{5}$ ao povo, a fim de deliberar sobre matéria de acentuada relevância, de natureza constitucional, legislativa ou administrativa, a fim de ratificar, conceder eficácia (condição suspensiva), ou retirar eficácia (condição resolutiva) de lei discutida e votada pelos representantes do povo. Pode-se dizer que o referendo distingue-se do plebiscito, pois há a existência prévia de um ato a ser aprovado ou reprovado pela soberania popular. No plebiscito, ao contrário, só haverá a atuação estatal após ser conhecida a vontade popular. $^{6}$

Segundo Manuel García-Pelayo, referendo é o direito que tem o

\footnotetext{
4 A Constituição de 1988 (artigo 14, II, e artigo 49, XV) consagrou o referendo, em termos normativos em sede constitucional, no direito brasileiro.

50 artigo $2^{\circ}, \S 2^{\circ}$, da Lei $n^{\circ}$ 9.709/98, dispõe que "o referendo é convocado com posterioridade a ato legislativo ou administrativo, cumprindo ao povo a respectiva ratificação ou rejeição".

6 A doutrina aponta ainda outras diferenças. Segundo José Luiz Quadros de Magalhães, "o que diferencia o referendo do plebiscito é a maior complexidade do primeiro, onde é colocado à apreciação popular do texto de uma lei, ou Constituição, enquanto que no plebiscito temos uma questão polêmica de interesse nacional, quando a complexidade da questão submetida à apreciação popular é menor (por exemplo, sim ou não ao parlamentarismo, ou a escolha entre presidencialismo e parlamentarismo). Acrescente-se ainda que no plebiscito a consulta popular se realiza antes da elaboração da norma, ao passo que o referendo tem caráter ratificador de uma Lei ou Constituição já elaborada". Cf. MAGALHÃES. Direito constitucional, t. 2, p. 389
} 
corpo eleitoral de aprovar ou rechaçar as decisões das autoridades constituídas. ${ }^{7} \mathrm{O}$ referendum vem sendo largamente utilizado atualmente nos casos de relevante interesse público, e a sua convocação dá-se após o ato objeto da consulta, cumprindo ao cidadão ratificá-lo ou rejeitá-lo. Da mesma forma que na decisão plebiscitária, também se pode afirmar que no referendo o resultado da consulta popular é sempre vinculante. ${ }^{89}$

Em certos casos a Constituição pode exigir que o referendo seja realizado, caso em que temos o referendo obrigatório. Referida exigência não está revista expressamente no texto constitucional brasileiro. Para Maria Victoria de Mesquita Benevides, "a consulta ao povo é obrigatória quando sua realização é condição indispensável para que a norma elaborada pelo Parlamento - ou o texto constitucional — possa ter vigência e validade". ${ }^{10}$ Adrian Sgarbi anota que o referendo será de realização obrigatória ou necessária "quando houver lei que expressamente o determine ou em razão da matéria ou tema decidendo, como em nosso sentir ocorre no caso brasileiro, se este for atinente à soberania popular". ${ }^{11}$ Mas tal exigência pode não existir, e o referendo será então previsto apenas como possibilidade, ficando a cargo do poder constituído decidir sobre a sua realização, por iniciativa de uma autoridade ou mediante solicitação formulada por um certo número de eleitores, hipótese em que haverá o referendo facultativo (ou referendo opcional). ${ }^{12}$ Nas palavras de Maria Victoria de Mesquita Benevides, os referendos "são facultativos, quando a Constituição confere a determinado órgão ou parcela do corpo eleitoral competência para requerer ou realizar consulta à população". ${ }^{13}$

Para Adrian Sgarbi ${ }^{14}$ uma decisão tomada por referendo obrigatório

\footnotetext{
7 GARCÍA-PELAYO. Derecho constitucional comparado, p. 183. Tradução nossa.

8 Nesse sentido está Maria Victoria de Mesquita Benevides: "Independentemente da omissão do texto constitucional brasileiro sobre o tema, creio razoável estabelecer que os referendos devem ter, sempre, caráter vinculante". Além disso, "mesmo nos países onde o referendo é meramente consultivo, o Parlamento pode se sentir moral e politicamente comprometido com o resultado das consultas". Cf. BENEVIDES. A cidadania ativa: referendo, plebiscito e iniciativa popular, p. 135.

9 Entretanto, Paulo Márcio Cruz pondera que "o referendo pode ser dividido em vinculante, que obriga à obediência ao resultado, sendo sua decisão superior hierarquicamente a qualquer outra, ou consultivo, no qual o resultado da 'consulta' popular seria um dado a mais, mas não o único a ser considerado na hora da tomada de decisão". Cf. CRUZ. Fundamentos de direito constitucional, p. 167-168.

10 BENEVIDES. A cidadania ativa: referendo, plebiscito e iniciativa popular, p. 141.

11 SGARBI. O referendo, p. 207-208.

12 Merecem ser conferidas as palavras de Manuel García-Pelayo: "Por su fundamento jurídico: a) Obligatorio, cuando es impuesto por la constitución como requisito necesario para la validez de determinadas normas legislativas. b) Facultativo, cuando su iniciativa depende de una autoridad competente para ello, por ejemplo, de una determinada fracción del cuerpo electoral o de las Cámaras, o del jefe del Estado". Cf. GARCIA-PELAYO. Derecho constitucional comparado, p. 183.

13 BENEVIDES. A cidadania ativa: referendo, plebiscito e iniciativa popular, p. 141.
} 
não pode ser alterada por uma norma superveniente que não acolha igual procedimento. Dessa forma, "se o Congresso Nacional achar por bem dispor novamente sobre a questão, deverá respeitar o trâmite de convocação obrigatória, pois em contrário norma jurídica não existirá”. Entretanto, para uma decisão tomada por referendo facultativo, deve-se considerar a legislatura em que foi realizado o referendo facultativo. Se a norma já foi conteúdo de referendo na mesma legislatura que se pretende fazer a alteração, "não pode ser feito, sob pena de desrespeitar o princípio da unidade da legislatura com ato incoerente e desarrazoado". Caso a norma tenha sido conteúdo de referendo em legislatura diversa da qual se deseja fazer a modificação, conclui Adrian Sgarbi "não haver embargo para a alteração de decisão tomada pelo povo".

O referendo pode ainda ser distinguido em referendo constituinte, referendo constitucional ou referendo legislativo. O referendo constituinte ocorre quando a Assembléia Constituinte convoca o corpo eleitoral para atuar no processo de elaboração de uma nova Constituição. O referendo constitucional é aquele atinente à reforma da Constituição. Já o referendo legislativo diz respeito às leis infraconstitucionais. ${ }^{15}$

No referendo constitucional facultativo ou obrigatório há uma autêntica participação do eleitorado no procedimento de reforma constitucional. ${ }^{16} \mathrm{O}$ referendo pode existir tanto na forma de votação popular de emenda constitucional efetuada pelo parlamento - o caso mais freqüente -, ou também na forma de participação do eleitorado através de iniciativa popular e sucessiva votação final, após o parlamento haver expressado sua atitude positiva ou negativa a respeito, caso este muito mais raro e que somente se encontra completamente estruturado na Suíça. ${ }^{17}$

\section{Iniciativa popular}

A iniciativa é o ato que deflagra o processo legislativo. Segundo Manoel Gonçalves Ferreira Filho, a iniciativa é o ato pelo que se propõe a adoção de direito novo, consistindo em "uma declaração de vontade,

14 SGARBI. O referendo, p. 207-210

15 SGARBI. O referendo, p. 241.

${ }^{16}$ Maria Victoria de Mesquita Benevides traz alguns dados do processo constituinte brasileiro: "Além da iniciativa popular, o projeto da 'comissão de sistematização' previa, igualmente, o referendo para deliberar sobre anulação total ou parcial de emenda à Constituição ou de lei, exigindo, para início de processo, a solicitação de $2 \%$ do eleitorado nacional. Trata-se do referendo por iniciativa popular, rejeitado no plenário pelo bloco do 'Centrão' (ver Jornal do Brasil, 14 jan. 1988: 'Centrão tira direitos dos cidadãos'). $\mathrm{O}$ anteprojeto Comparato e o projeto do PT previram referendo obrigatório para ratificar emendas constitucionais". Cf. BENEVIDES. A cidadania ativa: referendo, plebiscito e iniciativa popular, p. 143.

17 LOEWENSTEIN. Teoría de la constitución, p. 180. 
que deve ser formulada por escrito e articulada; ato que se manifesta pelo depósito do instrumento, do projeto, em mãos da autoridade competente". ${ }^{18}$ Quando a apresentação de determinado projeto de lei é imposta pela Constituição, tem-se a iniciativa vinculada; do contrário, trata-se de iniciativa facultativa. Embora a Constituição estabeleça a iniciativa reservada para certas matérias, v.g. artigo $61, \S 1^{\circ}$ da CF, a regra geral é que a iniciativa seja concorrente do Presidente da República, de qualquer deputado ou senador, de qualquer comissão da Câmara dos Deputados, do Senado Federal ou do Congresso Nacional, do Supremo Tribunal Federal, dos tribunais superiores, do procurador-geral da República e dos cidadãos (artigo $61 \mathrm{da} \mathrm{CF}$ ). Acerca desta última que se propõe a dedicar maior atenção.

A iniciativa popular confere ao povo o direito de apresentar uma proposta de emenda constitucional ou um projeto de lei. Constitui-se no ato do povo que dá início ao processo legislativo, mediante a propositura de projeto de emenda ou de lei por um certo número de eleitores. A iniciativa popular possibilita ao eleitorado participar do processo legislativo, ${ }^{19}$ cujos projetos não podem ser rejeitados por vício de forma. ${ }^{20}$ Segundo Luiz Pinto Ferreira, ${ }^{21}$ a iniciativa popular é "a instituição pela qual um grupo de pessoas pode propor uma lei ou sugestão de reforma constitucional, para tal necessitando de determinado número de assinaturas", permitindo-se ainda requerer a submissão desta proposta à apreciação dos eleitores, visando a sua aprovação ou rejeição. Constitui-se assim o direito do povo de introduzir projeto de lei e decidi-lo por votação nacional.

A apresentação do projeto popular ao órgão legislativo pode ocorrer através de um texto redigido de forma articulada e pronto para ser submetido à discussão e deliberação, hipótese em que se tem a iniciativa popular formulada, ou o documento apresentado pode restringir-se tãosomente a diretrizes gerais a respeito de uma matéria, contendo os con-

\footnotetext{
18 FERREIRA FILHO. Curso de direito constitucional, p. 186.

${ }^{19} \mathrm{Em}$ verdade a iniciativa popular tem sido muito pouco utilizada no Brasil. Lembra Márcia Maria Corrêa de Azevedo que "o famoso movimento popular em prol de um projeto de lei que classificasse os crimes hediondos denominou o PL n 04146, de 1993, de 'Projeto Daniela Perez ou Glória Perez'. A mobilização social deu-se em decorrência do repúdio provocado pelo assassinato da atriz Daniela Perez. O projeto citado foi aprovado nas duas Casas, sancionado e transformado na Lei n 8.930, de 6.9.1994. Entretanto, ele não foi um projeto de iniciativa popular. O Executivo atendeu a um apelo forte da sociedade e promoveu a iniciativa". Cf. AZEVEDO. Prática do processo legislativo, p. 370-371.

20 Exceto, naturalmente, o vício decorrente da ausência de subscrição do número mínimo de eleitores.

${ }^{21}$ FERREIRA. Curso de direito constitucional, p. 168.
} 
tornos gerais da medida que o povo deseja que seja apreciada, ocorrendo assim a iniciativa popular não-formulada (ou iniciativa popular simples), cabendo então aos representantes do povo dar forma legal ao seu conteúdo.

A Constituição brasileira de 1988 prevê a iniciativa popular, consistindo na apresentação à Câmara dos Deputados de projeto de lei subscrito por, no mínimo, um por cento do eleitorado nacional, distribuído pelo menos por cinco Estados, com não menos de três décimos por cento dos eleitores de cada um deles (artigo $61, \S 2^{\circ}, \mathrm{CF}$ ). Sem dúvida que tais exigências inibem a apresentação de projetos de lei de iniciativa popular.

Entretanto, não há obrigatoriedade na aprovação, por parte dos parlamentares, do projeto apresentado pelo povo. O que existe é tão-somente o dever de apreciação. Todavia, quanto maior for o número de eleitores que assinar o ato, mais difícil será a rejeição do projeto pelos parlamentares. Mas infelizmente, apesar da grande mobilização necessária para recolher o número mínimo de assinaturas, a Constituição brasileira sequer estabelece um prazo para que o Congresso aprecie o projeto de iniciativa popular, como faz a Constituição argentina (artigo 39). ${ }^{22}$

Diante da ausência de delimitação das matérias sobre as quais é cabível a utilização da iniciativa popular, conclui-se que as únicas restrições referem-se às matérias que a Constituição estabeleceu como de iniciativa privativa.

Embora a participação direta dos cidadãos esteja assegurada dentre os princípios fundamentais da República, a Constituição brasileira prevê expressamente a hipótese de iniciativa popular apenas para as leis complementares e ordinárias, ${ }^{23}$ não sendo expressa no que concerne às emendas constitucionais. ${ }^{24} \mathrm{~A}$ iniciativa para a apresentação de uma proposta de emenda constitucional, que ocorre na fase introdutória do processo legislativo, é conferida, na forma do artigo 60, caput e seus incisos, da CF, a um terço, no mínimo, dos membros da Câmara dos Deputa-

\footnotetext{
22 In verbis: "Los ciudadanos tienen el derecho de iniciativa para apresentar proyectos de ley en la Cámara de Diputados. El Congreso deberá darles expreso tratamiento dentro del término de doce meses".

${ }^{23}$ Art. 61, §2, CR: "A iniciativa popular pode ser exercida pela apresentação à Câmara dos Deputados de projeto de lei subscrito por, no mínimo, um por cento do eleitorado nacional, distribuído pelo menos por cinco Estados, com não menos de três décimos por cento dos eleitores de cada um deles".

24 Sayonara Grillo C. Leonardo da Silva esclarece que "durante o processo de revisão constitucional, determinado pelo Ato das Disposições Constitucionais Transitórias, a iniciativa popular foi inserida no Regimento Interno da Revisão através do mecanismo de subscrição de propostas assinadas por 15 mil eleitores e organizadas por três ou mais entidades legalmente constituídas. Vedou-se a apresentação de subscrição, por cada eleitor, de mais de três propostas. A admissão da iniciativa popular direta na proposição de alterações constitucionais deve ser entendida como conseqüência lógica da adoção dessa sistemática durante o processo Constituinte". Cf. SILVA. Poder reformador: insuficiência conceitual e experiências constitucionais, p. 51.
} 
dos ou do Senado Federal; ao Presidente da República; e a mais da metade das Assembléias Legislativas das unidades da Federação, manifestandose, cada uma delas, pela maioria relativa de seus membros. José Afonso da Silva, ${ }^{25}$ entretanto, admite que a Constituição brasileira possa ser emendada mediante proposta de iniciativa popular, fazendo-se uma interpretação sistemática, caso em que as percentagens previstas no $\S 2^{\circ}$ do art. 61 serão invocáveis. De fato, tem razão José Afonso da Silva, pois se o povo é o titular do poder, a iniciativa popular não deve ficar adstrita às leis infraconstitucionais, mas também deve ter a possibilidade de iniciar o processo de emenda à Constituição.

A Constituição brasileira de 1988 deixou para a lei a disciplina da iniciativa popular no processo legislativo estadual (artigo $27, \S 4^{\circ}, \mathrm{CF}$ ), e previu para os Municípios a competência de discipliná-la através da respectiva lei orgânica, observada, no entanto, a manifestação de pelo menos cinco por cento do eleitorado municipal (artigo 29, XIII, CF). É curioso que este dispositivo exija a manifestação de, pelo menos, cinco por cento do eleitorado. Não parece que o espírito da Constituição queira dificultar a participação popular no âmbito municipal, embora o texto constitucional imponha um limite mínimo a ser observado nos Municípios.

O direito norte-americano faz uma distinção entre duas espécies de iniciativa popular, que são a iniciativa direta e a iniciativa indireta. $\mathrm{Na}$ iniciativa direta, o projeto de emenda constitucional ou de lei infraconstitucional, subscrito pelo número mínimo de eleitores, deve ser obrigatoriamente submetido à deliberação dos eleitores nas eleições seguintes. Por outro lado, a iniciativa indireta possibilita que o Poder Legislativo estadual discuta e vote o projeto proposto pelos eleitores, que será submetido à aprovação popular apenas se for rejeitado pelo órgão legislativo.

Convém dizer que estas três formas de exercício democrático o plebiscito, o referendo e a iniciativa popular — permanecem ainda incipientes no corpo positivo constitucional brasileiro, ${ }^{26}$ passados muitos anos de vigência da ordem constitucional. Impõe-se a nós, além de concretizar tais conquistas, fortalecê-las com outras, como o veto popular. ${ }^{27}$

\footnotetext{
25 José Afonso da Silva anota ainda que "a Constituição não introduziu inovação de realce no sistema de sua modificação. Até a votação no Plenário, anteprojetos e projetos admitiam, expressa e especificamente, a iniciativa e o referendo populares em matéria de emenda constitucional. No Plenário, contudo, os conservadores derrubaram essa possibilidade clara que constava no $\$ 2^{\circ}$ do art. 74 do Projeto aprovado na Comissão de Sistematização. Não está, porém, excluída a aplicação desses institutos de participação popular nessa matéria". SILVA. Curso de direito constitucional positivo, p. 63-64.
} 


\section{Veto popular}

Deve ser dito, de início, que o veto popular ${ }^{28}$ não foi adotado pela Constituição Federal. O veto popular constitui-se na faculdade da qual o eleitorado é titular de se manifestar coletivamente contrário a determinada medida governamental ou lei já devidamente aprovada ou em vias de ser efetivada.

O veto popular distingue-se do veto do chefe do Poder Executivo, que ocorre na deliberação executiva do processo legislativo, pois neste caso existe a possibilidade do Poder Legislativo derrubá-lo com uma certa maioria de votos. ${ }^{29}$ No instituto do veto popular, é dado aos eleitores um prazo após a aprovação de um projeto pelo Poder Legislativo, que costuma variar entre sessenta e noventa dias, para que requeiram a aprovação popular. Antes do decurso de tal prazo a lei não entrará em vigor, e continuará suspensa até as eleições seguintes se houver a solicitação de um certo número de eleitores, ocasião em que o eleitorado decidirá se a lei terá vigência ou não. A rejeição do projeto importará em considerá-lo como se nunca tivesse existido.

Embora não previsto pela Constituição Federal, nada impede que os Estados-membros e os Municípios, no exercício do poder decorrente, adotem o veto popular nos seus respectivos âmbitos. Nesse sentido também está Regina Maria Macedo Nery Ferrari, ${ }^{30}$ entendendo que, "em nome da decantada autonomia dos Municípios e desde que afeto ao interesse local, pode-se admitir o veto popular, como resposta do eleitorado a consulta sobre existência de uma lei, que poderá, assim, ser revogada em processo de eleição direta".

Um aspecto desfavorável do veto popular é que ele implica no desprestígio do corpo de representantes, que tem o constrangimento de ver uma legislação por ele aprovada ser rejeitada pelo povo. Por outro lado,

\footnotetext{
${ }^{26}$ Merecem registro os muitos obstáculos colocados para o referendo popular, previsto no Estatuto do Desarmamento, para consultar a opinião do povo brasileiro acerca da venda de armas de fogo em todo o país. Cf. PEDRA. Ponto de vista: o referendo sobre a venda de armas. A Gazeta.

${ }^{27}$ A Proposta de Emenda Constitucional - PEC n 80/2003, de autoria do senador Antônio Carlos Valadares, propõe a alteração da redação do artigo 14 da Constituição Federal, inserindo incisos que criam dois novos institutos de democracia participativa: a revogação e o veto popular.

${ }^{28}$ Embora tenha sido proposto na época da elaboração da Constituição de 1988. Cf. BONAVIDES. Teoria constitucional da democracia participativa, p. 117.

${ }^{29} \mathrm{Cf}$. artigo $66, \S 4^{\circ}$, da CR, in verbis: "O veto será apreciado em sessão conjunta, dentro de trinta dias a contar de seu recebimento, só podendo ser rejeitado pelo voto da maioria absoluta dos Deputados e Senadores, em escrutínio secreto".

${ }^{30}$ FERRARI. Direito municipal, p. 30.
} 
entretanto, o veto popular dá a garantia ao povo de que não será submetido a uma norma que repudia. De certa forma, a finalidade do veto popular confunde-se com a do referendo. ${ }^{31}$

\section{Considerações finais}

O Estado Democrático de Direito, fundado no princípio da soberania popular, impõe a efetiva participação do povo nas decisões políticas, participação que não se exaure na mera formação das instituições representativas. Estas constituem um estágio da evolução do Estado Democrático, mas não o seu completo desenvolvimento. A democracia estritamente representativa não encontra mais legitimidade no Estado Moderno, especialmente no Brasil, onde por vezes se verifica a insatisfação dos representados em razão do comportamento dos seus representantes, que, não raras vezes, se comportam como substitutos do povo.

A renovação da teoria democrática assenta na formulação de critérios democráticos de participação política que não confinem esta ao ato de votar. Implica, pois, uma articulação entre democracia representativa e democracia participativa. O povo não pode ficar adstrito a se fazer presente somente nas eleições obrigatórias, mas é necessária uma efetiva participação popular na realização das atividades estatais. É imperioso que seja concretizada a democracia participativa, a fim de fazer valer a soberania popular, extraindo da Constituição todas as vontades do verdadeiro titular do poder - o povo. Em respeito ao princípio democrático, nos termos da Constituição, imprescinde constituir uma verdadeira democracia participativa, pluralista, que seja a garantia geral da vigência e eficácia dos direitos fundamentais.

É imperioso que seja observado o princípio democrático, inclusive respeitando a vontade da minoria e assegurando-lhe o direito de participar e expressar livremente sua opinião, podendo influir e até mesmo transformar a decisão majoritária, procedimento indispensável em um pluralismo político. A regra da maioria é uma das mais importantes normas de convivência em sociedade. Tal regra é uma prática importante onde as pessoas são politicamente iguais e tem interesses divergentes, e buscam uma solução pacífica para seus problemas, sem recorrer à força.

\footnotetext{
${ }^{31}$ Nas palavras de Dalmo de Abreu Dallari: "O veto popular é um instituto que guarda certa semelhança com o referendum, sendo mesmo denominado por autores norte-americanos de mandatory referendum". Cf. DALLARI. Elementos de teoria geral do estado, p. 154.
} 
O único meio capaz de viabilizar a participação jurídico-política dos cidadãos é através do exercício de uma série de instrumentos presentes no próprio ordenamento constitucional. A democracia participativa implica o exercício direto e pessoal da cidadania nos atos de governo.

Entretanto, as consultas populares encontram dificuldades onde a propaganda política é dominada pelos meios de comunicação social. Os cidadãos votantes têm a tendência, em nome de uma segurança, e demonstrando extremo medo do desconhecido, a não aprovarem normas que insiram inovações na convivência, mesmo que estas já se façam presentes em muitos outros países. Uma democracia participativa depende, assim, da existência de uma opinião pública ativa e informada, caso contrário tratar-se-ão de vontades efêmeras defendidas por maiorias cambiantes.

\section{Referências}

AZEVEDO, Márcia Maria Corrêa de. Prática do processo legislativo. São Paulo: Atlas, 2001.

BENEVIDES, Maria Victoria de Mesquita. A cidadania ativa: referendo, plebiscito e iniciativa popular. 3. ed. 5. impr. São Paulo: Ática, 2003.

BONAVIDES, Paulo. Teoria constitucional da democracia participativa. São Paulo: Malheiros, 2001.

CRUZ, Paulo Márcio. Fundamentos de direito constitucional. Curitiba: Juruá, 2001.

DALLARI, Dalmo de Abreu. Elementos de teoria geral do estado. 23. ed. São Paulo: Saraiva, 2002.

FERRARI, Regina Maria Macedo Nery. Direito municipal. 2. ed. rev. atual. e ampl. São Paulo: RT, 2005.

FERREIRA, Luiz Pinto. Curso de direito constitucional. 11. ed. ampl. atual. São Paulo: Saraiva, 2001.

FERREIRA FILHO, Manoel Gonçalves. Curso de direito constitucional. 27. ed. atual. São Paulo: Saraiva, 2001.

GARCÍA-PELAYO, Manuel. Derecho constitucional comparado. Madrid: Alianza Universidad Textos, 1993.

LOEWENSTEIN, Karl. Teoría de la constitución. Tradução de Alfredo Gallego Anabitarte. Barcelona: Ariel, 1976.

MAGALHÃES, José Luiz Quadros de. Direito constitucional. Belo Horizonte: Mandamentos, 2002. t. 2.

PEDRA, Adriano Sant'Ana. A Constituição viva: poder constituinte permanente e cláusulas pétreas. Belo Horizonte: Mandamentos, 2005.

PEDRA, Adriano Sant'Ana. Ponto de vista: o referendo sobre a venda de armas. A Gazeta,

A \& C R. de Dir. Administrativo e Constitucional, Belo Horizonte, ano 7, n. 27, p. 109-120, jan./mar. 2007 
Vitória, 17 abr. 2005.

PEDRA, Adriano Sant'Ana. Possibilidade de edição de medidas provisórias pelos municípios. Interesse Público. ano 2. n. 8. out./dez. 2000. São Paulo: Notadez, 2000. p. 91-99.

SGARBI, Adrian. O referendo. Rio de Janeiro: Renovar, 1999.

SILVA, José Afonso. Curso de direito constitucional positivo. 20. ed. rev. atual. São Paulo: Malheiros, 2002.

SILVA, Sayonara Grillo C. Leonardo da. Poder reformador: insuficiência conceitual e experiências constitucionais. Rio de Janeiro: Lumen Juris, 1997.

Informação bibliográfica deste texto, conforme a NBR 6023:2002 da Associação Brasileira de Normas Técnicas (ABNT):

PEDRA, Adriano Sant'Ana. Participação popular no processo legislativo. A\&C Revista de Direito Administrativo e Constitucional, Belo Horizonte, ano 7, n. 27, p. 109-120, jan./ mar. 2007. 